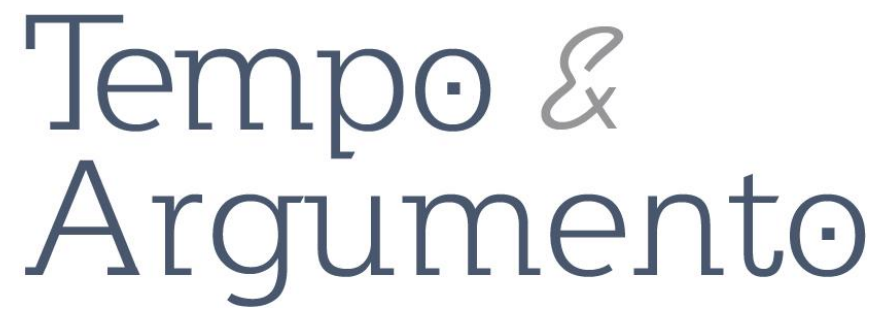

\title{
Uma história oral narrada por vozes femininas na luta contra as hierarquias de gênero
}

\section{Resenha da obra:}

ROVAI, Marta Gouveia de Oliveira (ORG). História oral e história das mulheres: rompendo silenciamentos. São Paulo: Letra e Voz, 2017.

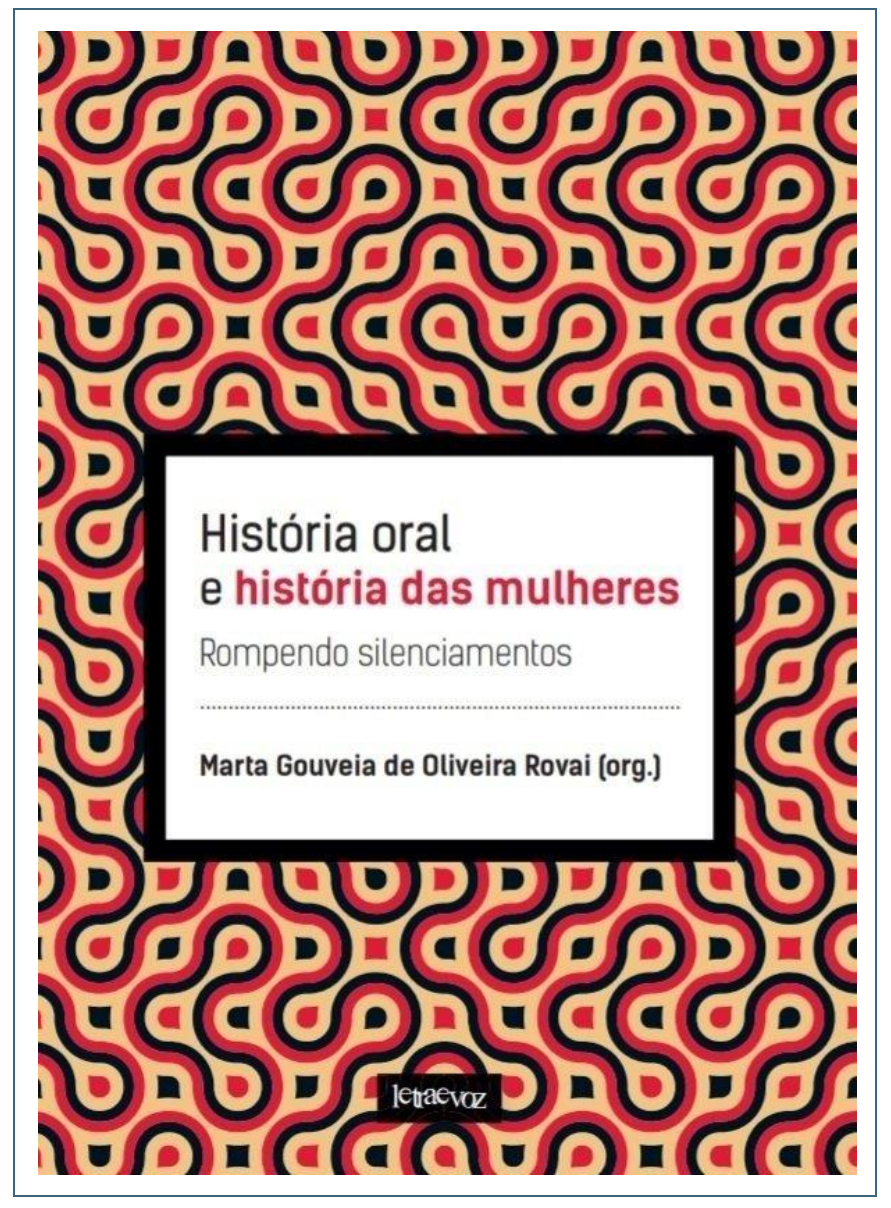

\section{Autora da resenha}

Amanda Arrais Mousinho Mestranda em Estudos Culturais na Universidade de São Paulo (USP).

São Paulo, SP - BRASIL amandaarraism@gmail.com orcid.org/0000-0002-3441-7619

Para citar esta resenha:

ROVAI, Marta Gouveia de Oliveira (ORG). História oral e história das mulheres: rompendo silenciamentos. São Paulo: Letra e Voz, 2017. Resenha de: MOUSINHO, Amanda Arrais. Uma história oral narrada por vozes femininas na luta contra as hierarquias de gênero. Revista Tempo $e$ Argumento, Florianópolis, v. 11, n. 26, p. 630 - 634. jan./abr. 2019. 
"História oral e história das mulheres: Rompendo silenciamentos" é um livro composto por estudos baseados nas vidas de mulheres de diferentes origens territoriais, sociais, culturais e políticas e suas relações com os homens, com o propósito de refletir sobre essas experiências femininas diante das mais diversas práticas culturais que perpassam o cotidiano. Segundo a organizadora da obra, Marta Gouveia de Oliveira Rovai, essas mulheres detêm a possibilidade de se manifestar, por intermédio da história oral, contra toda forma de opressão, indiferença e esquecimento com o objetivo de publicizar e enfrentar dores na luta contra o silenciamento.

O livro tem início com uma entrevista realizada com Rachel Soihet no intuito de contar a trajetória da estudiosa de gênero e história das mulheres. Realizada por Natália de Santanna Guerellus, a entrevista descreve o percurso pessoal e profissional de Rachel e narra como o fato de as mulheres ocuparem espaços separados nas festas e comporem rodas de conversa cujos temas eram casa e filhos - enquanto homens debatiam temas como política e negócios - acabou por despertar seu interesse sobre o estudo da divisão de papéis entre homens e mulheres.

Mais adiante, a pesquisadora tenta compreender de que forma a segregação e a opressão sofridas pelas mulheres prejudicavam suas potencialidades intelectuais e profissionais, e também defende a complementariedade dos estudos de gênero e da história das mulheres. A entrevistada se denomina feminista ao buscar direitos para as mulheres de modo a constituir uma sociedade igualitária com a qual contribui em termos intelectuais, por exemplo, fazendo uso da história oral para trazer à tona temas que não foram explorados nas décadas anteriores e resgatar, através de memórias, uma história até então não registrada.

O restante do livro é dividido em três partes, sendo cada parte composta por dois capítulos. A primeira parte, "Narrativa de militância feminina: Desvelando relações hierarquizadas de gênero", debate a relação entre gênero, feminismo e ditadura buscando compreender de que forma as relações de gênero afetam a narrativa e a trajetórias de mulheres que participaram de algum tipo de militância. 
No primeiro capítulo, "Viver o gênero na clandestinidade", Joana Maria Pedro aborda a experiência de mulheres militantes que vivenciaram a clandestinidade. A autora faz uso da história oral para entrevistar mulheres que, após se conectarem às organizações políticas, tiveram que utilizar a clandestinidade como recurso para fugir da repressão no período da ditadura no Brasil. Durante as entrevistas, as memórias foram utilizadas como fonte e, por mais que algumas mulheres tenham exercido protagonismo político ao desempenhar cargos de destaque, o que chama a atenção é o fato de algumas das mulheres entrevistadas se colocarem à sombra de seus parceiros ao desqualificarem a própria militância, o que reforça a hierarquia de gênero vigente e minimiza a atuação feminina nos espaços públicos e políticos que são tidos como naturalmente masculinos. Segundo Joana Pedro, essa autodesqualificação da mulher militante reitera que a memória é gendrada e, por consequência, a forma como histórias são narradas e rememoradas também o são, o que acaba por fazer com que o reconhecimento das mulheres na condição de sujeitos históricos e protagonistas seja atravessado por relações de gênero.

No segundo capítulo, intitulado "Ditadura civil-militar e relações de gênero: Uma análise das experiências de mulheres na guerrilha urbana no eixo Brasília-Goiânia”, Eloísa Pereira Barroso e Clerismar Aparecido Longo entrevistam mulheres que militaram na organização de guerrilheiras urbanas que se apresentou como resposta à repressão ditatorial. Nesse caso, a entrevista oral visou entender a condição gendrada da mulher nesse movimento, abarcando hierarquias e estratégias de poder, bem como compreender como os discursos dos sujeitos envolvidos em projetos políticos de esquerda estão condicionados a configurações de gênero.

Já a segunda parte do livro, "Experiências desviantes: a ousadia de ser mulher em contextos autoritários", tem início com o capítulo "O herói e a deslocada: História oral, gênero, ditadura, emoções". Escrito por Ana Maria Veiga, o estudo explora a vida de Valdir Alves e Elaine Borges: jornalistas que exerceram a profissão durante a censura da ditadura civil-militar. A autora frisa que apesar de ambos os sujeitos terem tido formação profissional semelhante, o gênero feminino e masculino - opostos e hierarquizados foram definitivos na construção de uma experiência divergente separada por um abismo 
do binarismo, de forma que Valdir ficou conhecido como herói e mito, enquanto Elaine não ganhou o mesmo título, mas sim o de "incendiária do cenário político" (2017, p. 92), que poderia prejudicar a imagem dos jornalistas por gostar de criar confusão. E é por isso que Ana Maria Veiga nomeia Elaine como “deslocada”, pelo fato de a jornalista ter se destacado em um meio profissional predominantemente masculino e fugir do suposto papel tradicional da mulher.

No segundo capítulo, "Médica, resistente e condessa: A história da militante potiguar Laly Carneiro Meignan", a autora Maria Cláudia Badan Ribeiro narra a vida da primeira mulher potiguar a ser presa por motivos políticos devido à sua militância ir de encontro com o coronelismo, as oligarquias rurais e a ala conservadora do Rio Grande do Norte. Laly, uma mulher nordestina, médica, militante, exilada e professora consagrada no exterior, faz parte de uma resistência construída coletivamente que utilizava como instrumento principal a educação popular.

Na terceira e última parte do livro, "O privado como dimensão pública: Rompendo territórios", as autoras exploram temas que abarcam a naturalização das funções sociais das mulheres em uma sociedade patriarcal. No primeiro capítulo, "Ser mãe ou não ser: Afinal, qual é a questão? A história oral desvendando o mito do amor materno", Marcela Boni Evangelista entrevista dois grupos de mulheres que vivenciaram a experiência da maternidade na adversidade. Primeiramente, a autora conversou com mulheres-mães de jovens envolvidos com atos infracionais que foram privados de liberdade; e em um segundo momento, Marcela conversou com mulheres que passaram pela experiência do aborto induzido, o que evidencia a maternidade enquanto uma escolha. Em ambas as situações, a história oral serviu como instrumento para dar voz a essas mulheres a fim de problematizar a ideia do mito do amor materno, bem como a imposição da obrigatoriedade da maternidade para que a mulher alcance a plenitude. Nesses dois casos, a história oral aproxima o leitor das realidades obscurecidas pelas quais passam essas mulheres diante de uma função social a elas atrelada e que é há muito tempo naturalizada.

No capítulo final, "Romper o silenciamento: Narrativas femininas sobre violência de gênero e desvitimização", Marta Gouveia de Oliveira Rovai e Naira de Assis Castelo 
Branco relatam casos de mulheres piauienses, moradoras da Parnaíba, que sofreram violência de gênero no período de 1995 a 2014. Segundo as autoras, ouvir as vítimas de violência simboliza o incentivo a uma reflexão acerca das relações entre domínio público e privado e a tentativa de desconstruir a ideia de que a violação dos direitos no espaço privado é um assunto conjugal. Entretanto, é primordial ressaltar que, apesar da violência sofrida, as mulheres não podem ser reduzidas ao papel de vítima, logo, o papel da história oral, nesse caso, é justamente o de fazer com que esses testemunhos atinjam a esfera pública a fim de criar medidas protetivas e desnaturalizar violências e hierarquias de gênero.

No decorrer dos capítulos desse livro, o que se percebe é a necessidade de assegurar às mulheres o direito de contar suas próprias experiências de modo que suas histórias não sejam reduzidas a uma narrativa terceirizada contada sob a ótica masculina. Em vista disso, a história oral funciona como instrumento metodológico ao dialogar diretamente com essas mulheres e permitir que suas experiências sejam publicizadas sem a mediação de instituições atravessadas por uma cultura permeada por práticas e discursos androcêntricos.

Recebido em 25/08/2018

Aprovado em 15/10/2018

Universidade do Estado de Santa Catarina - UDESC Programa de Pós-Graduação em História - PPGH Revista Tempo e Argumento Volume 11 - Número 26 - Ano 2019 tempoeargumento@gmail.com 